\begin{tabular}{|c|c|c|}
\hline $\begin{array}{l}\text { PKS } \\
\text { PUBLIC } \\
\text { KNOWLEDGE } \\
\text { PROJECT }\end{array}$ & $\begin{array}{c}\text { Revista de GEOGRAFIA } \\
\text { (RECIFE) } \\
\text { http://www.revistauffe.br/revistageografia }\end{array}$ & $\begin{array}{l}\text { OJS } \\
\frac{\text { OJEN }}{\text { OPENAL }} \\
\text { SYSTEMS }\end{array}$ \\
\hline
\end{tabular}

\title{
TRANSFORMACIÓN DEL PAISAJE CULTURAL EN LA REGIÓN DEL CHACO SEMIÁRIDO DE LA PROVINCIA DE SALTA EN EL SIGLO XXI
}

\author{
Gisela Soledad Córdoba ${ }^{1}$, María Cristina Camardelli ${ }^{2}$ \\ 1 Doutorado em Ciências Sociais com orientação em Geografia, UNT, IBIGEO-CONICET. Email: \\ cordobagisela@gmail.com \\ ${ }^{2}$ Mestre em Desenvolvimento de Zonas Áridas e Semiáridas, UNSa. Email: criscamardelli@yahoo.com.ar
}

Artigo recebido em 05/08/2017 e aceito em 01/10/2017

\begin{abstract}
RESUMEN
Las transformaciones del paisaje cultural, debidas a la expansión del fenómeno urbano en el territorio y al desarrollo de actividades productivas, han alcanzado un ritmo severo en las últimas décadas en el chaco semiárido de la provincia de Salta, en el cual se observan cambios profundos sobre el territorio y consecuentemente sobre sus habitantes tradicionales: comunidades aborígenes y pequeños productores ganaderos; asociado al arribo de emprendimientos agropecuarios empresariales. Se analiza la transformación del paisaje cultural en un sector del chaco semiárido al sudeste del departamento San Martín en la primera década del siglo XXI, según las formas de apropiación del paisaje e impulsores de cambio intervinientes. Se constata que, las formas de apropiación del paisaje chaqueño implementadas por los empresarios agropecuarios, se asocian al aprovechamiento de unos pocos servicios ecosistémicos con una postura estática y de dominio de la naturaleza; sin importar el efecto que sus actividades generan sobre el paisaje cultural pese a las políticas ambientales vigentes. Mientras que los pequeños productores ganaderos y comunidades aborígenes presentan estrategias de producción y reproducción asociadas al aprovechamiento de múltiples servicios ecosistémicos desde una visión holística del paisaje, con prácticas sociales tradicionales.
\end{abstract}

Palabras claves: transformación, paisaje cultural, apropiación del paisaje

\section{TRANSFORMATION OF THE CULTURAL LANDSCAPE IN THE REGION OF THE SEMIARID CHACO OF THE PROVINCE OF SALTA IN THE 21ST CENTURY}

\begin{abstract}
The transformation in the cultural landscape, due to the expansion of the urban phenomenon in the territory and the development of productive activities, have reached a severe rhythm in the last decades in the semi-arid Chaco of the province of Salta, in which there are intensive changes over the territory and consequently about its traditional habitants: Aboriginal communities and small livestock producers; associated with the arrival of entrepreneurial agricultural enterprises. We analyze the transformation of the cultural landscape in a sector of the semi - arid Chaco to the southeast of the department of San Martín in the first decade of the 21st century, according to the forms of appropriation of the landscape and drivers of change involved. It is verified that the forms of appropriation of the Chaco landscape implemented by the agricultural entrepreneurs are associated to the use of a few ecosystem services with a static and dominion of the nature; regardless of the effect that their activities generate on the cultural landscape in spite of the existing environmental policies. While small livestock producers and Aboriginal communities present production and reproduction strategies associated with the use of multiple ecosystem services from a holistic view of the landscape, with traditional social practices.
\end{abstract}

Keywords: Transformation. Cultural landscape. Appropriation of landscape. 


\section{INTRODUCCIÓN}

Las transformaciones del paisaje, debidas a la expansión del fenómeno urbano en el territorio y al desarrollo de actividades productivas, no son nuevas, pero en las últimas décadas han alcanzado un ritmo antes desconocido. Los cambios ocurridos en los paisajes de cualquier territorio, reflejan la esencia misma de los comportamientos de las sociedades.

El paisaje es determinante en la construcción de las culturas e identidades colectivas y es un importante instrumento de interpretación del territorio (Gómez Alzate, 2010).

Carl Ortwin Sauer, padre de la geografía cultural norteamerica, expresó: "El paisaje cultural está formado a partir de un paisaje natural por un grupo cultural. La cultura es el agente, el área natural es el medio, el paisaje cultural es el resultado. Bajo la influencia de una cultura dada, el paisaje se somete a cambios a través del tiempo, pasando por fases, y probablemente alcanzando en última instancia el final del ciclo de desarrollo" (Gregory, 2009). En este sentido, el paisaje cultural refleja el comportamiento humano sobre el territorio.

Las formas de intervención y de apropiación del paisaje han estado condicionadas por la manera de ver y entender la naturaleza, donde la valoración cultural de una comunidad en constante interacción con su ambiente, condiciona la dinámica particular del territorio y, en consecuencia se traduce en transformaciones del paisaje cultural (Gómez Alzate, 2010).

El chaco semiárido de la provincia de Salta, constituye un sector significativo para analizar la transformación del paisaje cultural, en el cual se observan cambios profundos sobre el territorio y consecuentemente sobre sus habitantes tradicionales: familias originarias wichi y pequeños productores ganaderos criollos. Esta transformación se asocia al arribo de grandes emprendimientos agropecuarios empresariales, particularmente en la primera década del siglo XXI. Los cambios que se están operando en el territorio son un tema de debate y confrontación tanto entre los propios pobladores de la región como para académicos y sectores políticos, mientras que para algunos podrían ser causa de degradación social y ambiental para otros indican el arribo del desarrollo a la región. Por ello, en el presente trabajo se planteó la necesidad de analizar la transformación del paisaje cultural en un sector del chaco semiárido correspondiente al sudeste del departamento San Martín de la provincia de Salta en la primera década del siglo XXI; según las formas de apropiación del paisaje e impulsores de cambio intervinientes; a partir de información secundaria y primaria, entrevistas a informantes claves y observaciones participantes. 


\section{CARACTERIZACIÓN AMBIENTAL DEL PAISAJE CHAQUEÑO}

El territorio se caracteriza por severas restricciones ambientales con un largo período seco (de abril a octubre) y precipitaciones escasas concentradas en el verano (diciembre a marzo), con una media de $576 \mathrm{~mm}$ y altas temperaturas (hasta $50 \mathrm{C}^{\circ}$ ), sin embargo la zona no es exenta de heladas (Figura 01).

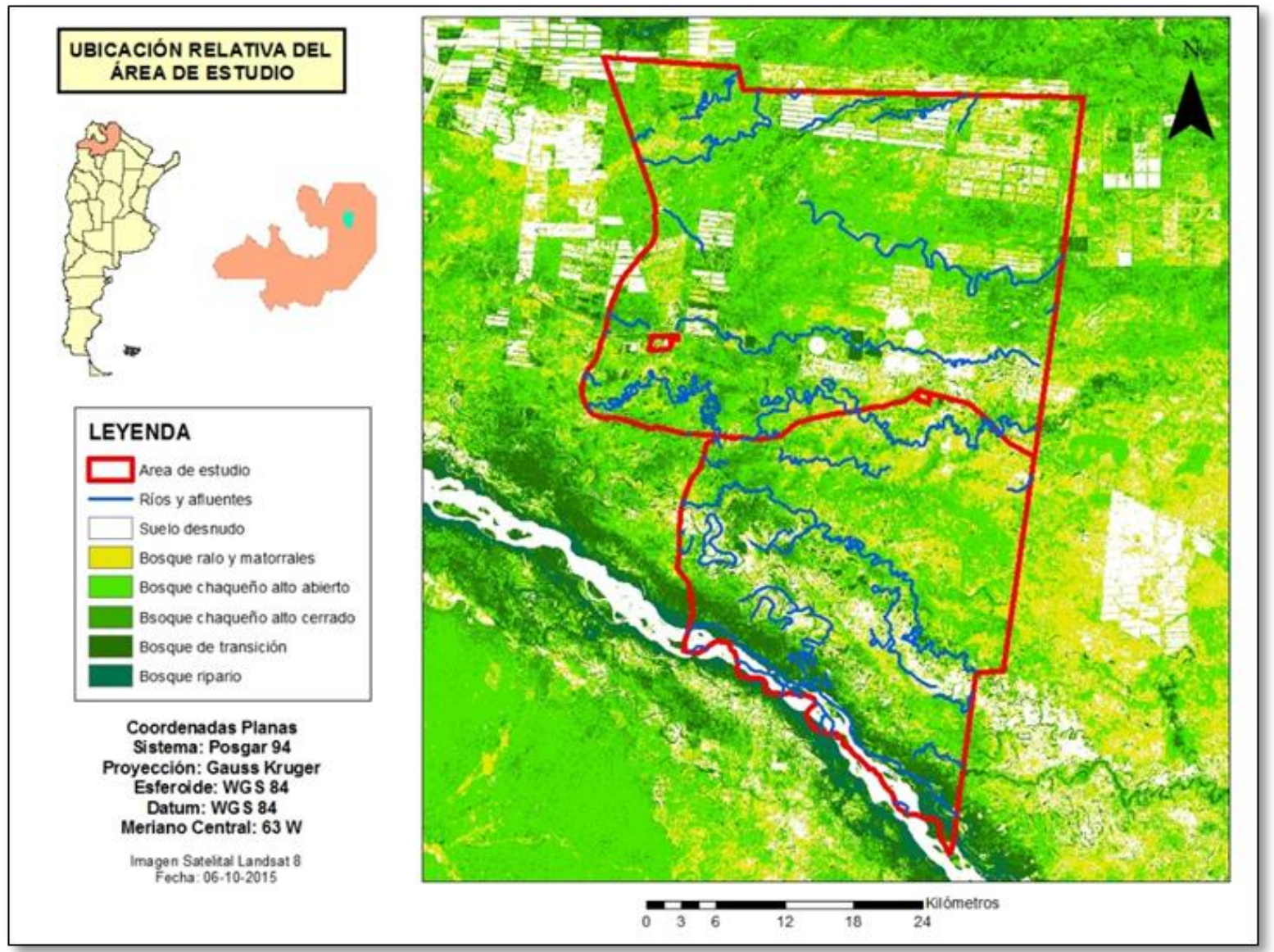

Figura 01: Caracterización ambiental del área de estudio. Sudeste del departamento San Martín, provincia de Salta, Argentina. Fuente: Elaboración propia.

La red fluvial presenta un diseño desordenado y con una pendiente general del terreno inclinada levemente hacia el sudeste con una franja de gran horizontalidad donde se forman bañados, lagunas, ciénagas, esteros, madrejones o meandros de antiguos cauces que acumulan el agua de lluvia formando humedales, los que se mantienen con agua desde el verano a mediados del invierno, y se secan totalmente en las calurosas primaveras. La mayor parte de la población utiliza estas efímeras fuentes superficiales tanto para el consumo de las personas como del ganado, lo que constituye una severa amenaza para la calidad de vida de las familias y afecta sus sistemas productivos (Figura 02). Respecto al agua subterránea, por 
costos y/o falta de atención del estado el acceso a estas fuentes de agua es restringido para los pobladores del sector rural.

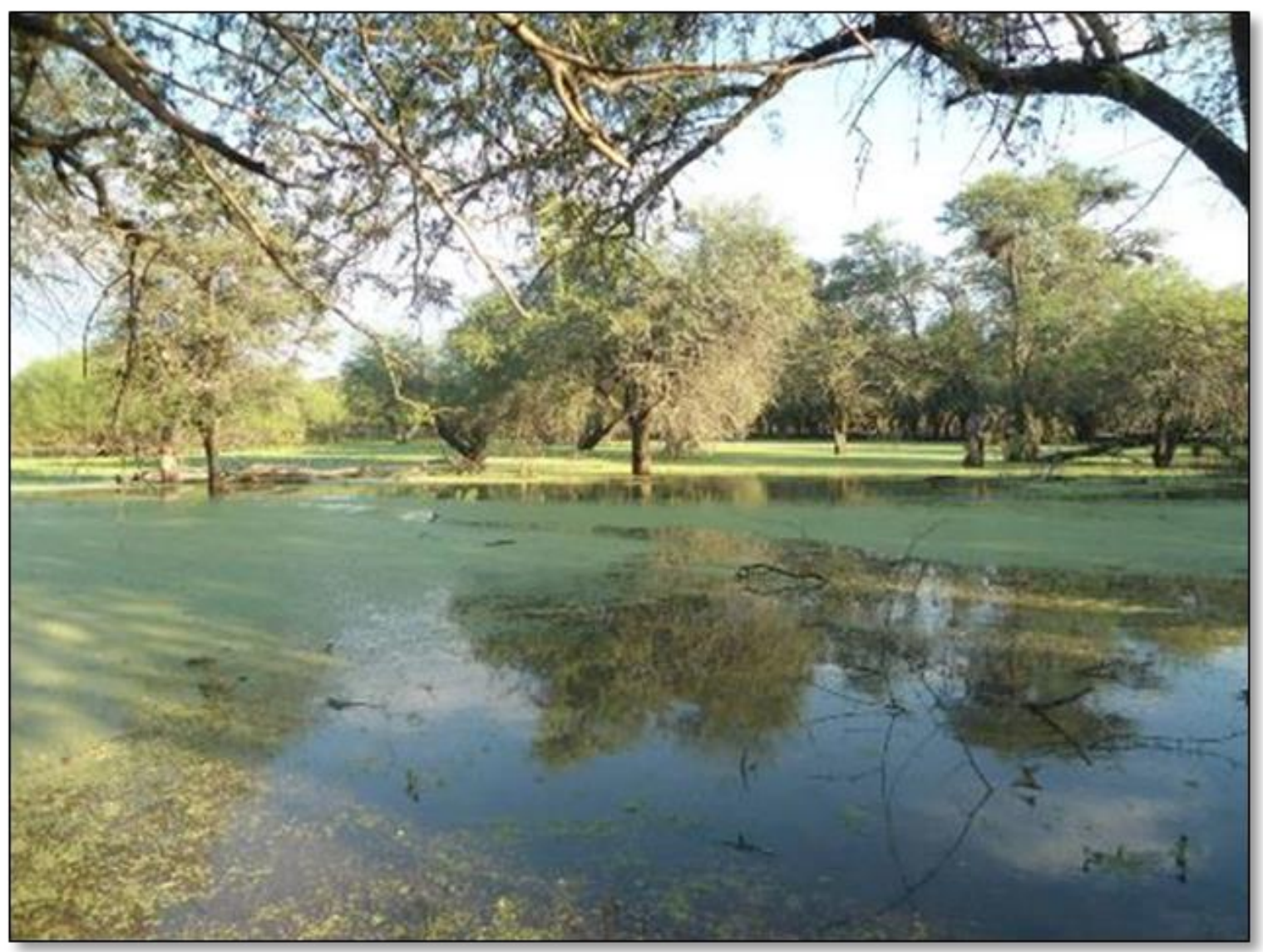

Figura 02: Madrejón de un Puesto cercano a la localidad de Pluma de Pato, provincia de Salta. Fuente: Gisela Córdoba, Marzo 2015.

Fisonómicamente en el área bajo estudio, se encuentran representados: el bosque de transición y el bosque chaqueño, este último se manifiesta en tres subtipos bosque alto cerrado, bosque alto abierto y bosque ralo o matorrales. Sobre las márgenes del río Bermejo se ubica un sector de bosque ripario.

Bosque de transición y bosque ripario: aportan madera de alta calidad y altos índice de producción, las especies arbóreas que predominan son: Geoffroea decorticans (chañar), Chloroleucon tenuiflorum (espinillo o palo hediondo), Pisonia ambigua (caspi zapallo), Anadenanthera colubrina (horco cebil), Calycophyllum multiflorum (palo blanco), Maclura tinctoria (mora amarilla), Enterolobium contortisiliquum (pacará), Caesalpinia paraguariensis (guayacán) y Prosopis alba (algarrobo blanco); en los sectores del bosque ripario en las márgenes del rio Bermejo aparece ceiba rosada (Erythrina dominguezii). 
Bosque chaqueño alto abierto/ Bosque chaqueño alto cerrado: la mayor superficie del territorio se encuentra cubierta con bosque chaqueño típico de los dos quebrachos. La diferencia entre bosque abierto o cerrado depende de la cobertura que ambos presentan. Las especies arbóreas que predominan en el bosque chaqueño son: Aspidosperma quebrachoblanco (quebracho blanco), Schinopsis quebracho colorado (quebracho colorado santiagueno), Bulnesia sarmientoi (palo santo), Caesalpinia paraguariensis (guayacán), Calycophyllum multiflorum (palo blanco), Phyllostylon rhamnoides (palo amarillo), Prosopis alba (algarrobo blanco), Schinus molle (molle), Tabebuia nodosa (palo cruz). La productividad disminuye, así también el valor de las maderas.

Bosque chaqueño ralo y matorrales: Corresponde a un bosque abierto que si bien presenta ejemplares de quebracho blanco y colorado se caracteriza por la presencia de un estrato arbustivo espinoso denso, con presencia de palo cruz y palo santo. El estrato arbustivo está conformado por duraznillos bajos (Ruprechtia triflora), garabato (Acacia praecox), iscayante (Mimizyganthus carinatus), pata pata (Ximenia americana), teatin (Acacia furcatispina), poroto de monte (Capparis retusa). En tanto los matorrales, corresponden a una unidad dominada por 2 especies arbustivas (pichana o retama y poleo), con la presencia de escasos ejemplares de quebracho blanco. Arbustivas encontradas: pichana o retama (Cassia aphylla), poleo (Lippia sp), tusca (Acacia curvifructa), brea (Cercidium praecox), mistol de zorro (Castela coccinea) bola verde (Capparis speciosa), poroto de monte (Capparis retusa).

Los suelos conforman un complejo mosaico, la mayor parte de la superficie se encuentra cubierta por Haplustalfes imperfectamente drenados y Natracualfes sodicos sin capacidad para efectuar cultivos y con fuerte limitaciones para la implantación y la producción sostenida de pasturas, también es importante la presencia de Haplustoles que corresponde a suelos de textura arenosa excesivamente drenados, lo que también los torna inadecuados para la labranza y la implantación de pasturas (Camardelli y Salazar, 2013). Los suelos de mayor capacidad de uso (Argiustoles) solo aparecen en el extremo oeste y en pequeños lunares en el resto del territorio ${ }^{1}$.

\footnotetext{
${ }^{1}$ Al respecto de la calidad de los suelos un asesor de reconocido prestigio en la provincia enfatiza: La experiencia me marca que el chaco salteño, con respecto a los suelos, el $90 \%$ de la superficie a partir de los 45 a $65 \mathrm{~cm}$ de profundidad en el suelo tenemos presencia de sales, por lo tanto es importantísimo evitar que se erosione el suelo, es muy somera la profundidad sin sal.
} 


\section{GRUPOS CULTURALES Y FORMAS DE APROPIACIÓN DEL PAISAJE CHAQUEÑO}

\section{Comunidades aborígenes}

Las comunidades aborígenes pertenecen a la etnia wichi ${ }^{2}$, son cazadores recolectores. Algunas familias se dedican a la agricultura (choclo, zapallito, anco, sandía, tomate, pimiento) en pequeñas huertas, cuyo destino es el autoconsumo y sus excedentes se destinan a la venta. Además, fabrican artesanías (cucharas y platos) para venta; y practican la actividad pesquera en aquellas comunidades que están cercanas al río.

Las actividades de caza y recolección de los grupos indígenas de la región chaqueña, se caracterizan por una enorme diversidad en el uso de la tierra y de los recursos naturales. Sin embargo, la disponibilidad de estos servicios ecosistémios, se ha ido reduciendo a medida que aumentaron las restricciones ambientales y territoriales impuestas por el avance de las agro-empresas y también por la gran presión de extracción forestal que realizaron las propias comunidades y los anteriores dueños.

Tal es así que, desde la llegada del hombre blanco, los grupos indígenas han ido perdiendo la cultura propia de los pueblos cazadores y recolectores, aunque la mayoría tiene arraigadas costumbres de vida con dependencia plena de la naturaleza y aún conservan elementos de su rica cosmovisión, su lengua y curaciones naturales, entre otras cosas.

Según Buliubasich y Rodriguez (2009), para estos pueblos el medio ambiente no es sólo un "proveedor incesante, estático e inagotable de materias primas o recursos naturales de los cuales se sirven apara su alimentación, salud y equipamientos sino que constituye además su hogar y el de sus muertos", conviven con la naturaleza en íntima relación, entendida ésta, como el entorno concreto de su vida.

\section{Pequeños productores ganaderos}

Los pequeños productores ganaderos, son conocidos como puesteros criollos. El puesto, como unidad de producción y vivienda abastece de bienes alimentarios y algunos no alimentarios para el autoconsumo. Crían ganado vacuno, caprino, ovino y porcino para el autoconsumo y para el mercado local y regional, en situación de tenencia precaria de la tierra. La ganadería se realiza de manera extensiva a campo abierto, lo que implica el pastaje sin

\footnotetext{
${ }^{2}$ Los Wichí, como los restantes grupos étnicos chaquenses desarrollaron su sistema cultural y social sobre el contexto ecológico del chaco (Buliubasich y Rodriguez, 2009, p.23). 
límites definidos, con baja inversión en infraestructura aprovechando los recursos que ofrece el bosque chaqueño, es decir, dependen netamente de la oferta de forraje del monte.

$\mathrm{El}$ acceso y disponibilidad de agua, junto a la oferta de forraje nativo provisto por el monte, constituyen los servicios más importantes para el desarrollo de ésta ganadería. La mayoría de los puestos cuentan con pozos, de los cuales extraen agua para consumo animal en época de sequía, mientras que en épocas de lluvias el agua es consumida por los animales desde madrejones y aguadas.

Otros servicios que obtienen del bosque corresponden a la caza y recolección de productos madereros y no madereros para consumo familiar o para la construcción de infraestructura en el puesto. Debido a las restricciones climáticas, las actividades agrícolas se reducen a la producción de pequeños cercos para autoconsumo.

Las prácticas sociales llevadas a cabo por los pequeños productores, se asocian al aprovechamiento de múltiples servicios ecosistémicos, tal como fue mencionado anteriormente; sin embargo, los años de presión sobre los recursos, sumados a la propia fragilidad del ecosistema chaqueño, han causado la desaparición del estrato herbáceo, lo que lleva a que el ganado consuma exclusivamente renovales de especies arbóreas y arbustivas y algunas especies del estrato subarbustivo, lo que es causa de una baja productividad en los rodeos y podría afectar los servicios que brinda el bosque (Camardelli y Salazar, 2013). Al respecto un técnico asesor explica: "El monte les dio comida a las vacas de por vida, y se espera que el monte siga dando comida...si se ordena el rodeo, el monte dará mejor comida y se bajará la presión".

Desde la percepción de los actores del territorio, los principales problemas para producir no son atribuidos a sus propias prácticas sino a los rigores climáticos propios de la zona; así también a las dificultades para acceder a tecnologías, créditos, y capacitaciones (Camardelli y otros, 2015).

Para éste tipo social, la apropiación de los servicios podría estar limitada por el régimen de tenencia de la tierra, en la mayoría de los casos son ocupantes, es decir, sin título de la tierra. Esto genera dos situaciones en los pequeños productores, en algunos casos es causa de desaliento para realizar mejoras, y en otros, reafirman su posición realizando las mejoras aun cuando esto les genera conflictos con los dueños de la tierra cuando pretenden tomar posesión de la misma. 


\section{Empresarios agropecuarios}

Los sistemas empresariales son principalmente ganaderos, dado que las bajas precipitaciones no posibilitan la producción a secano en la zona (sólo se constató la existencia de una finca agrícola con un sistema de riego pivot). Los empresarios realizan una ganadería vacuna de cría, con destino de la producción a los mercados locales y nacionales, obteniendo ingresos considerablemente mayores en comparación con los pequeños productores criollos, sin embargo dado los altos costos de mantenimiento, las ganancias han decaído en los últimos tiempos, un empresario ganadero de la zona explicó: "Si los ingresos no mejoran, pienso en vender la finca”.

Esta actividad, se realiza a expensas de un acelerado reemplazo de bosques nativos por pasturas monofíticas, entre las cuales se mencionan: Panicum maximun (gatton panic), Cenchrus ciliari (pasto búfalo) y Chloris gayana (grama rhodes); para lo cual se efectúan distintas técnicas de desmontes totales o selectivos, que comprenden la remoción total o parcial de la cobertura arbórea, arbustiva y sub-arbustiva del bosque chaqueño. Se realiza un manejo rotativo del ganado, a través de potreros alambrados, en los cuales se renuevan las pasturas cada cierto tiempo empleando arados o rolos y siembra.

Esta forma de apropiación de los servicios en el sector empresarial, está regulada por la aplicación en éste territorio de la Ley 7.543 de Ordenamiento Territorial de los Bosques Nativos de Salta, que zonificó el área en la categoría II (amarillo), sólo permite el manejo de bosques y la implementación de sistemas silvo pastoriles, por lo tanto, no están autorizados los desmontes totales o selectivos. Al respecto, ésta regulación de acceso a los servicios (forraje para el ganado), fue considerada para el sector agro-empresarial como "un freno a la producción"; mientras que para el sector ambientalista como... "un avance sin precedentes en materia ambiental y un ejemplo de la importancia de la participación de la sociedad civil, constituyendo una herramienta esencial para empezar a solucionar la emergencia forestal en la que se encuentra Argentina” (Greenpeace, 2009 en Camardelli y Salazar 2013).

Como se puede ver, las prácticas sociales empresariales se relacionan con el uso de muy pocos servicios, tales como gramíneas forrajeras para el ganado y la fertilidad del suelo para pasturas, lo que ya fue descripto por Cáceres y otros (2015, p.62).

Esta forma de apropiación intensiva de servicios ecosistémicos, acarrea pérdidas de biodiversidad (Córdoba, 2013, p.45) y de calidad de los suelos (Caruso, 2010, p.103), y podría llevar en el mediano o largo plazo no solo a la caída de la estabilidad económica al 
nivel predial sino a la pérdida de la sustentabilidad social y ambiental al nivel territorial (Camardelli y otros, 2007, p.34).

\section{TRANSFORMACIÓN DEL PAISAJE CULTURAL CHAQUEÑO EN EL SIGLO XXI}

La región chaqueña, si bien conserva grandes extensiones no transformadas a agricultura sobre ambientes semiáridos, distan de ser bosques prístinos, dado que desde principios del siglo $\mathrm{XX}$ han sido alterados de forma severa por la ganadería extensiva, la extracción de madera, leña y carbón, y por la caza de subsistencia (Bucher y Huszar, 1999 en Grau y otros, 2009).

No obstante, a fines del siglo XX e inicios del siglo XXI, vino a sumarse el avance de la ganadería empresarial sobre zonas consideradas marginales para la agricultura pero aptas para el desarrollo de sistemas ganaderos o mixtos. Esta última etapa coincide con el fenómeno global llamado "Revolución Verde" (Pengue, 2005 en Schmidt, 2014), por el cual los rindes de producción aumentaron en el sector agrícola debido a crecientes insumos externos, en la que se manifestaba la capacidad de respuesta de los cultivares e híbridos al fertilizante, la maquinaria o el riego; que trajo aparejado la introducción del cultivo de soja transgénico con el paquete tecnológico de siembra directa en la región pampeana. En ésta región producir grano se volvió más rentable y, generó una competencia por la tierra, y el desplazamiento de la ganadería hacia zonas más marginales lo que en definitiva produjo un proceso de ganaderización de la región semiárida chaqueña. Se constata en ésta región un período de venta masiva de tierra pública sin normativas de manejo; quien compraba podía hacer lo que le placiera con los recursos del ecosistema chaqueño.

Los nuevos productores instalados en la región chaqueña, desarrollaron una ganadería basada en desmontes totales para la implantación de pasturas. Se habla de la "pampeanización" del chaco: la importación del sistema de manejo pampeano (de capitalización creciente, ahorrativo en mano de obra e intensivo en insumos, maquinaria e infraestructura, dinamizado por grandes productores) sobre regiones subtropicales con diferentes características socio productivas y ecológicas (Schmidt, 2014). Se trata de un modelo exitoso y rentable en el corto plazo, en perjuicio de las externalidades en el largo plazo: pérdidas de rendimiento y fertilidad de los suelos, aumento en los procesos de degradación y erosión, pérdida de biodiversidad, entre otras consecuencias (Pengue, 2009; Prudkin, 1997; Reboratti, 1996b; Slutzky, 2005 en Schmidt, 2014). 
Según Pengue (2005 en Schmidt, 2014), "Pampeanizar" significa pensar y actuar como si los paquetes tecnológicos y los tipos de uso del suelo fueran intercambiables entre ecorregiones muy distintas, y que todo lo que se hace en la Ecorregión Pampa puede hacerse en la región chaqueña. Este concepto, supone que los ecosistemas naturales funcionan y responden de manera similar ante cualquier disturbio; sin embargo sabemos que no es así y es lógico que aparezcan rápidamente consecuencias ambientales y sociales de este proceso de fuerte incorporación de tecnología y capital.

Entre las principales consecuencias ambientales del avance del frente agropecuario, por un lado, produjo una fragmentación del paisaje con sus efectos en distintas intensidades en los recursos flora, fauna, agua y suelo. En cuanto a consecuencias sociales, la instalación de emprendimientos agropecuarios en la región, generó conflictos sociales entre los viejos y nuevos actores por la tierra. Los criollos y comunidades aborígenes, en su mayoría, fueron desplazados de sus territorios sobre los cuales hacían uso de servicios ecosistémicos indispensables para su reproducción social.

Este nuevo proceso de cambio implica que el conflicto entre la producción de alimentos y la conservación de la naturaleza se superpone con un conflicto entre productores modernos capitalistas (orientados a economías globales de mercado) y productores tradicionales (con economías mixtas entre subsistencia y mercados locales).

Los pedidos de habilitaciones productivas con fines ganaderos son los que toman cada vez mayor relevancia, lo cual estaría dando cuenta del progresivo corrimiento de la frontera agropecuaria hacia el este de la región (Figura 03).

Durante el período 2004-2015, se desmontaron 1.002.657 hectáreas de bosque nativo en la región chaqueña de la provincia de Salta, por lo cual representa la transformación más grande y más severa por habilitaciones de cambios de usos del suelos, particularmente en el año 2007 previo a la aprobación de la Ley Nacional 26.331 de Presupuestos Mínimos de Protección Ambiental de los Bosques Nativos, conocida como la "Ley de Bosques" sancionada en noviembre de ese año. Dicha ley suspendió el otorgamiento de nuevas autorizaciones hasta que las provincias sancionaran sus respectivas leyes de OTBN (Leake y otros, 2016). 


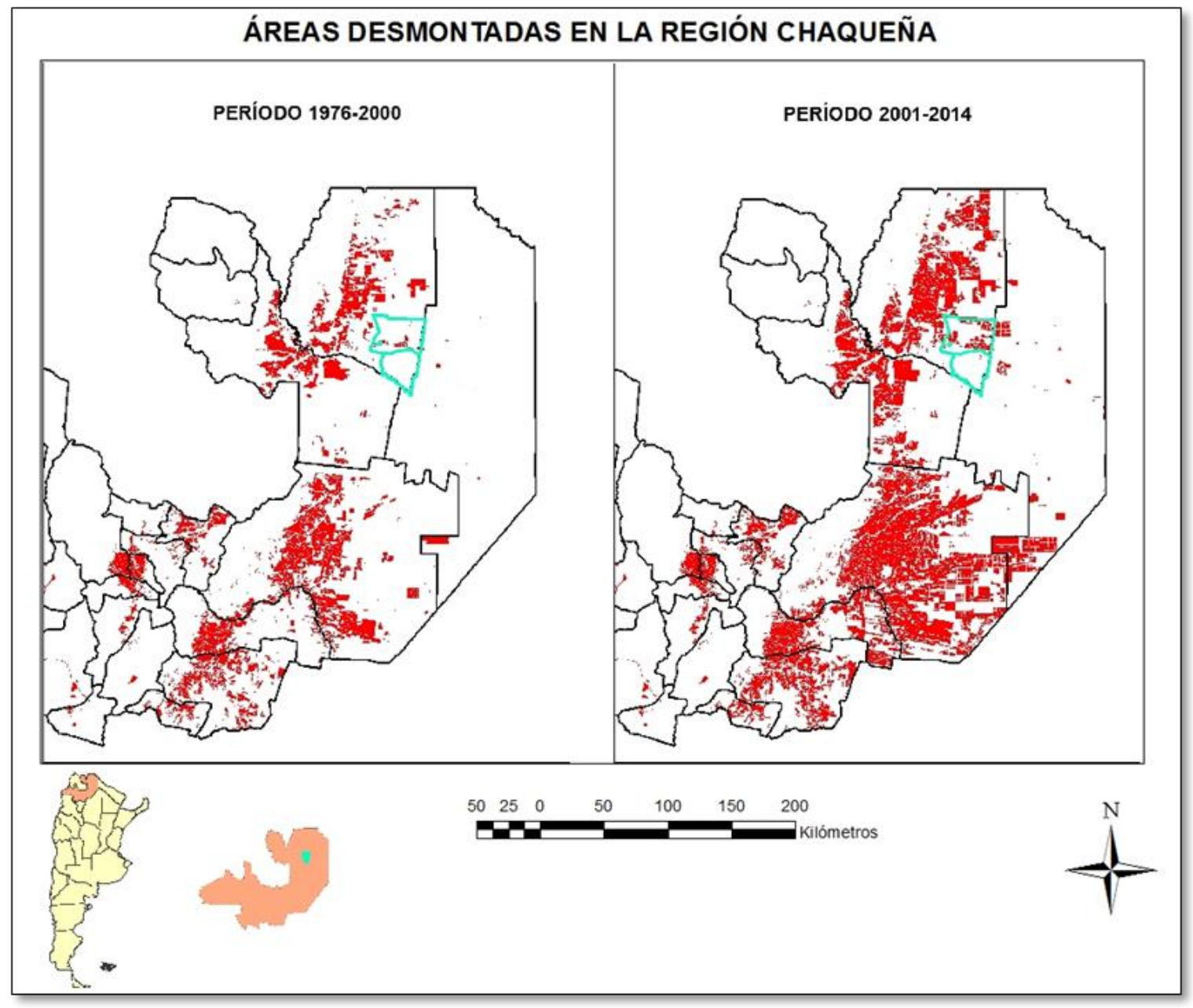

Figura 03: Áreas desmontadas en la región chaqueña, período 1976-2014. Fuente: Elaboración propia.

La provincia de Salta cumplió con el mandato de la Ley de Bosques mediante la sanción de la Ley Provincial 7543 de Ordenamiento Territorial de los Bosques Nativos, promulgada en diciembre del 2008, que zonificó el área en la categoría II (amarillo), sólo permite el manejo de bosques y la implementación de sistemas silvo pastoriles, por lo tanto, no están autorizados los desmontes totales o selectivos. Al respecto, ésta dificultad para acceder a los servicios (forraje para el ganado) fue descripta por un empresario de la siguiente manera: "En mi finca no puedo desmontar para sembrar pasturas porque está dentro de la zona amarilla...los pequeños productores están mejor que nosotros", ésta expresión del productor está referida a que los pequeños productores tienen más acceso a los servicios que ofrece el bosque (forraje) que los mismos empresarios.

Pese a la sanción de la Ley de Bosques en Salta en el año 2008, el gobierno provincial posteriormente realizó recategorizaciones prediales, a solicitud del titular de la 
finca en zonas con bosques nativos que habían sido clasificados en las Categorías I - rojo y II - amarillo (donde está expresamente prohibido hacerlo) (Greenpeace, 2014).

Cabe señalar que la normativa nacional (Ley 26.331- Presupuestos Mínimos de Protección Ambiental de los Bosques Nativos), no permite realizar recategorizaciones prediales de los Ordenamientos Territoriales de Bosques Nativos, y su decreto reglamentario dicta que "en caso de duda respecto de la afectación de un predio en forma total o parcial, se optará por la categoría de mayor valor de conservación”. Recién, en diciembre de 2014 se prohibió por decreto (Dcto. 3.749/14) las "recategorizaciones" que antes y también por decreto (Dcto. 2.211/10) se habían autorizado para permitir el avance de las topadoras sobre zonas protegidas por la normativa nacional y su correlato provincial. Oficiales datos adicionales muestran que en los últimos 2 años, 2015 y 2016, el número de hectáreas de bosques derribadas bajó considerablemente.

Las tecnologías de habilitación de tierras de alto impacto, son llevadas a cabo sin importar el efecto que genera sobre el paisaje natural; esto se podría asociar a la valoración de unos pocos servicios ecosistémicos por parte de éstos actores sociales. Frente a ésta problemática, a nivel Nacional se planteó un Plan de Manejo de Bosques con Ganadería Integrada (MBGI) compatible con la Ley 26.331, al cual Salta se adhirió a través de un convenio firmado el 17 de septiembre del 2016. El convenio tiene como objetivo general armonizar las políticas públicas dirigidas a la preservación de los bosques nativos con las vinculadas al desarrollo de la actividad ganadera, contribuyendo al diseño de modelos productivos sustentables de los bosques nativos como una alternativa frente al cambio de uso del suelo que posibilita compatibilizar: producción, conservación y la gente que vive en las zonas de bosque. Sin embargo, ésta opción no termina de convencer a ningún sector: organizaciones ambientalistas protestan por el desmonte de miles de hectáreas bajo éste sistema y entidades de productores reclaman por la falta de oportunidades para expandir la frontera agropecuaria.

A la fecha, el Ministerio de Ambiente y Producción Sustentable de la Nación se encuentra trabajando en la actualización del Plan de Ordenamiento Territorial, a los fines de realizar un balance de 10 años de políticas ambientales e informar el estado de los bosques nativos. Al respecto, la provincia de Salta dejó en evidencia un fracaso de la política ambiental en lo que refiere al cuidado de los bosques nativos y las comunidades que viven en ellos. Por lo tanto, es de esperar que el no cumplimiento de ésta normativa, produzca un 
impacto ambiental significativo $\mathrm{y}$ afecte seriamente a muchas comunidades criollas e indígenas.

\section{CONSIDERACIONES FINALES}

La investigación realizada, pone de manifiesto la transformación del paisaje cultural en el chaco semiárido salteño en la primera década del siglo XXI, asociado al arribo de sistemas empresariales agropecuarios principalmente al norte del área de estudio, sector ocupado tradicionalmente por comunidades aborígenes y pequeños productores ganaderos que fueron desplazados de sus territorios.

Las formas de apropiación del paisaje chaqueño implementadas por estos nuevos actores, se asocian al aprovechamiento de unos pocos servicios ecosistémicos con una postura estática y de dominio de la naturaleza; y a la disponibilidad de mayores recursos financieros que les permite una intensificación de la ganadería con: alambrados perimetrales, maquinarias de alta tecnología y mano de obra contratada. Las tecnologías de habilitación de tierras de alto impacto, son llevadas a cabo sin importar el efecto que genera sobre el paisaje cultural de la región chaqueña pese a las políticas ambientales vigentes.

Los pequeños productores ganaderos y comunidades aborígenes presentan estrategias de producción y reproducción asociadas al aprovechamiento de múltiples servicios ecosistémicos desde una visión holística del paisaje, con prácticas sociales tradicionales que se relacionan principalmente a cuestiones culturales, es decir, la transferencia de conocimiento local de generación en generación. Sin embargo, desde hace algunos años, organizaciones provinciales y nacionales vienen trabajando en la zona para lograr una producción más sustentable y reducir de ésta manera la presión que ejercen sobre el bosque chaqueño; pero respetando la identidad productiva de cada actor social.

En toda transformación de un paisaje subyace un modelo de vida sobre otro, y es necesario identificar un modelo de vida nuevo que genera nuevos paisajes donde se integren la naturaleza y la cultura (Gómez Alzate, 2010). La comprensión de los cambios en los paisajes es un instrumento clave para poder redefinir la gestión y la planificación de los recursos naturales que exigen las sociedades contemporáneas. Para interpretar estos procesos de cambio, requiere un planteamiento de la investigación desde una base conceptual apropiada; específicamente implica una perspectiva transdisciplinar. El paisaje debe considerarse como un hecho de interés general, como patrimonio ambiental, cultural y 
productivo, y como una fuente inagotable de conocimiento en constante transformación que demanda cada vez mayor compromiso social.

\section{REFERENCIAS}

BULUIBASICH, C., y RODRÍGUEZ, H. Panorama etnográfico, histórico y ambiental. En: C. BUluibASICH, C., y GONZÁleZ, A. (coords). Los Pueblos indígenas en la provincia de Salta-La posesión y el dominio de sus tierras Departamento San Martín. Salta, Argentina: CEPIHA, 2009.

CÁCERES, D.M., TAPELLA, E., QUÉTIER, F., y DÍAZ, S. The social value of biodiversity and ecosystem services from the perspectives of different social actors. Revista Ecology and Society. Canadá, v.20, n.1, 19 p, 2015. Disponible en: <http://dx.doi.org/10.5751/ES-07297200162>. Acceso en: 12 ago. 2015.

CAMARDElli, M.C., CARUSO, H., MIRANDA, S., VOlANTE, J., y BIANCHI, A. Cambios de uso de la tierra y adopción de tecnologías ganaderas en el Chaco Semiárido Salteño. Parte I: Departamento Anta. En: $3^{\circ}$ Jornadas de la Asociación Argentino Uruguaya de Economía Ecológica. Tucumán, Argentina: 2007. 59 p.

CAMARDELli, M.C., y SALAZAR, N. Territorio, Ambiente y Poder en la Región Chaqueña de la Provincia de Salta. En: MANZANAL, M., y PONCE, M. (Orgs). La desigualdad ¿del desarrollo? Controversias y disyuntivas en el desarrollo rural en el norte Argentino. Buenos Aires, Argentina: Fundación CICCUS, 2013.

CAMARDElli, M. C.; CÓRDOBA, G. S; PÉREZ DE BIANCHI, S., y REYES, S. Ganadería en el chaco salteño: Impactos generados sobre el ecosistema desde la percepción de los actores del territorio. En: IX Jornadas Interdisciplinarias de Estudios Agrarios Agroindustriales Argentinos y Latinoamericanos. Buenos Aires, Argentina: 2015. 20 p.

CARUSO, V.H. Evaluación de la sustentabilidad ambiental mediante indicadores del uso de la tierra en sistemas ganaderos del chaco salteño. 2010. Tesis (Maestría) - Universidad Nacional de Mar del Plata, Buenos Aires.

CÓRDOBA, G.S. Efectos de las prácticas de mantenimiento sobre la estructura de la vegetación leñosa de un sistema silvopastoril del Chaco Salteño. 2013. Tesis (Grado) Facultad de Ciencias Naturales, Universidad Nacional de Salta, Salta. 
GÓMEZ ALZATE, A. El paisaje como patrimonio cultural, ambiental y productivo. Revista KEPES. Colombia, v.7, n.6, p.91-106, ene-dic. 2010. Disponible en: <http://vip.ucaldas.edu. co/kepes/downloads/Revista6_6.pdf>. Acceso en: 14 jul. 2016.

GREGORY, D (Ed.). The dictionary of human geography (5th ed). Malden, MA: Blackwell, 2009.

GRAU, R.H., GASPARRI, I.N., y GASPARRI, M.A. Cambio y eficiencia de uso del territorio en el chaco argentino: el conflicto entre producción de alimentos y conservación de la naturaleza en distintas escalas. p.390-407, 2009.

GREENPEACE. Desmontes S.A Parte 2: La responsabilidad empresarial y gubernamental en la violación de la Ley de Bosque en Salta. Argentina, 2014. 34 p. Disponible en: <http://m.greenpeace.org/argentina/Global/argentina/report/2014/bosques/DesmontesSA2dap arte.pdf>. Acceso en: 18 oct. 2016.

LEAKE, A., LÓPEZ, O.E, y LEAKE, M.C. La Deforestación del Chaco Salteño 20042015. Salta, Argentina: SMA, 2016. 61 p.

SCHMIDT, M.A. (Des)ordenamientos territoriales salteños. Una aproximación al contexto previo al Ordenamiento Territorial de Bosques Nativos en la provincia de Salta. Revista Mundo Agrario, La Plata, v.15, n.28, 2014. 